\title{
Imaging plasma docosahexaenoic acid (dha) incorporation into the brain in vivo, as a biomarker of brain DHA: Metabolism and neurotransmission
}

\author{
Stanley I. RAPOPORT \\ Epolia RAMADAN \\ Mireille BASSELIN
}

Brain Physiology and Metabolism Section, National Institute on Aging, Building 9, room 15128, National Institutes of Health, Bethesda, MD 20892, USA

$<$ sir@helix.nih.gov >
Docosahexaenoic acid (DHA, 22:6n-3), an $n-3$ polyunsaturated fatty acid (PUFA), is essential for maintaining normal brain structure, function and metabolism, and its brain concentration depends on dietary DHA content and liver synthesis of DHA from its shorter chain dietary precursors, particularly $\alpha$-linolenic acid ( $\alpha$-LNA (18:3n-3)) (Gao et al., 2009a). DHA participates in signal transduction, gene transcription and other important functions, and is a precursor for neuroprotectins, resolvins and other antiinflammatory products (Bazan, 2009; Salem et al., 2001).

Multiple rodent studies have demonstrated that prolonged dietary n-3 PUFA deprivation, from 15 weeks to as long 3 generations, results in reduced brain DHA content within individual phospholipids, associated with increased brain concentrations of docosapentaenoic acid (DPA)n-6 (22:5n-6) largely derived from liver biosynthesis (Salem et al.,

\begin{abstract}
Docosahexaenoic acid (DHA) is critical for normal brain structure and function, and its brain concentration depends on dietary DHA content and hepatic conversion from its dietary derived $n-3$ precursor, $\alpha$-linolenic acid $(\alpha-L N A)$. We developed an in vivo method in rats using quantitative autoradiography to image incorporation into brain of unesterified plasma DHA, and showed that the incorporation rate equals the rate of brain metabolic DHA consumption. Thus, quantitative imaging of DHA incorporation from plasma into brain can be used as a biomarker of brain DHA metabolism and neurotransmission. The method has been extended to humans with the use of positron emission tomography (PET). Furthermore, imaging in unanesthetized rats using DHA incorporation as a biomarker in response to $N$-methyl-D-aspartate (NMDA) administration confirms that regional DHA signaling is independent of extracellular calcium, and likely mediated by a calcium-independent phospholipase $A_{2}$ (iPLA $A_{2}$ ). Studies in mice in which iPLA $A_{2}$ VIA $(\beta)$ was knocked out confirmed that this enzyme is critical for baseline and muscarinic cholinergic signaling involving $D H A$.
\end{abstract}

Key words: docosahexaenoic acid, $\mathrm{PPLA}_{2}, C P L A_{2}$, brain, biomarker, imaging, positron, arachidonic, calcium, rat, human, PET

2001). These studies generally involved euthanization and direct chemical analysis of brain lipid content, limiting our ability to interpret in vivo brain DHA metabolism and kinetics. In view of conflicting evidence that low dietary intake of DHA-containing fish products is correlated with multiple human brain diseases, including Alzheimer disease, and that dietary DHA supplementation may be helpful in some of these conditions (Conquer et al., 2000; Quinn et al., 2010), it would be useful to have an in vivo biomarker of regional brain DHA consumption that could be used in awake animals and in humans to test the efficacy of DHA supplementation and other experimental or clinical conditions. Further, it would be useful to understand DHA participation in signal transduction, thus if DHA incorporation into brain might be used as a biomarker of regional brain metabolism and neurotransmission in health and disease.
Neither arachidonic acid (AA, 20:4n-6) nor DHA can be synthesized de novo from 2 carbon chains in vertebrates (Holman, 1986). Both long-chain PUFAs enter the brain from the circulation, but quantitation of their rates of entry as well as of their disposition within brain have remained controversial. In a study involv-

\begin{tabular}{|ll|}
\hline \multicolumn{2}{|c|}{ Abbreviations } \\
DHA & docosahexaenoic acid \\
AA & arachidonic acid \\
DPA & docosapentaenoic acid \\
$\alpha-L N A$ & $\alpha$-linolenic acid \\
EPA & eicosapentaenoic acid \\
PLA $_{2}$ & phospholipase $A_{2}$ \\
CPLA $_{2}$ & cytosolic PLA \\
sPLA $_{2}$ & secretory PLA \\
iPLA $_{2}$ & calcium-independent PLA \\
NMDA & N-methyl-D-aspartate \\
PUFA & polyunsaturated fatty acid \\
PET & positron emission tomography \\
\hline
\end{tabular}

To cite this article: Rapoport SI, Ramadan E, Basselin M. Imaging plasma docosahexaenoic acid (dha) incorporation into the brain in vivo, as a biomarker of brain DHA. Metabolism and neurotransmission. OCL 2011; 18(5): 246-250. doi : 10.1684/ocl.2011.0396 
ing feeding a radiolabeled fatty acid to rats (Purdon et al., 1997), we showed that only after its hydrolysis from circulating lipoprotein was its brain uptake measurable, and at a rate equivalent to the rate following injecting the unesterified fatty acid intravenously, thus arguing for uptake of the unesterified fatty acid. This finding was supported by studies in mice genetically lacking lipoprotein receptors (Chen et al., 2008). Calculations of on-off kinetics of unesterified fatty acids bound to serum albumin indicate that about $5 \%$ of the fatty acid is removed from albumin as blood passes through brain (Robinson et al., 1992).

Once having entered brain, unesterified DHA is largely (>80\%) and selectively delivered via an acyl-CoA synthetase and acyltransferase to the stereospecifically numbered $s n-2$ position of phospholipids, while its precursors $\alpha$-LNA or eicosapentaenoic acid (EPA, 20:5n-3) are largely $\beta$-oxidized within mitochondria after transfer by carnitine acyltransferase (Chen et al., 2011; DeGeorge et al., 1991; DeGeorge et al., 1989; DeMar et al., 2005; Gavino and Gavino, 1991). Additionally, elongases and desaturases that can convert the $\mathrm{n}-3$ precursors to $\mathrm{DHA}$, while present, have very low brain activities and are unaffected by dietary n-3 PUFA deprivation (Igarashi et al., 2007).

It is possible to calculate and image the rate of incorporation of unesterified unlabeled DHA in a single study in an unanesthetized rodent, by infusing radiolabeled $\left[1-{ }^{14} \mathrm{C}\right] \mathrm{DHA}$ intravenously and measuring regional incorporation coefficients $k^{*}$ into brain using quantitative autoradiography, then multiplying the unlabeled concentration of unesterified plasma DHA by the incorporation coefficient to calculate the incorporation rate, $J_{\text {in, }}$ of unlabeled DHA, where the asterisk identifies labeled plasma or brain concentrations of DHA (Robinson et al., 1992).

$$
\begin{aligned}
& k^{*}=\frac{C_{\text {brain }(D H A)}^{*}}{\int_{0}^{T} C_{\text {plasma }(D H A)}^{*}} \\
& J_{\text {in }}=k^{*} C_{\text {plasma }(D H A)}
\end{aligned}
$$

Doing this gives a whole brain incorporation rate of DHA equal to about 0.19 $\mu \mathrm{mol} / \mathrm{gram}$ brain per day in the adult rat
(Contreras et al., 2000). Confirmation that this calculated incorporation rate from a single study equals the rate of whole brain DHA consumption was derived from separate studies in multiple rats in which $\left[4,5-{ }^{3} \mathrm{H}\right] \mathrm{DHA}$ was injected into the cerebral ventricles and brain DHA radioactivity and concentrations were followed in animals killed animals from 0 to 60 days thereafter. A whole brain half-life of 33 days was calculated for DHA, giving a daily rate of DHA consumption of $0.25 \mu \mathrm{mol} / \mathrm{g} /$ day (DeMar et al., 2004), equivalent to the single injection value considering the variance of the data. The efficiency and simplicity of the single injection measurement, using quantitative autoradiography, makes it ideal for measuring whole brain DHA consumption.

Additional measurements with intracerebroventricular $\left[4,5-{ }^{3} \mathrm{H}\right] \mathrm{DHA}$ showed that 15 weeks of dietary n-3 PUFA deprivation prolonged the DHA half-life in brain to 90 days and reduced brain DHA consumption to $0.06 \mu \mathrm{mol} / \mathrm{g} /$ day, while downregulating expression of calcium-independent phospholipase $A_{2}$ (iPLA $A_{2}$ )-VIA ( $\beta$ ) (Rao et al., 2007). In vitro studies indicate that this enzyme is selective for the hydrolysis of DHA from membrane phospholipid (DeMar et al., 2004; Garcia and Kim, 1997; Strokin et al., 2004). The observed downregulation of enzyme expression with would be expected to help to preserve brain DHA. As DHA metabolites, many of which are antiinflammatory and include neuroprotectins and resolvins, are the major pathways of DHA metabolic loss in brain (Bazan, 2009), these results provided a basis for the reduced resistance to neuroinflammation and cognitive dysfunction in animals subjected to dietary n-3 PUFA deprivation (DeMar et al., 2006; Farooqui et al., 2007).

The equivalence between $J_{\text {in }}$ for DHA calculated from an intravenous infusion injection at a single time point, and the DHA consumption rate calculated by intracerebroventricular injection followed by sampling brain from multiple animals over a 60-day period, indicates that the single time point measurement represents a biomarker of brain DHA consumption. Accordingly, we synthesized positron-labeled $\left[1-{ }^{11} \mathrm{C}\right] \mathrm{DHA}$ and conducted studies using positron emission tomography (PET) to quantitatively image incorporation of unesterified plasma DHA into the brain of adult healthy human volunteers (Channing and Simpson, 1993; Umhau et al., 2009). Values of incorporation coefficients $k^{*}$ for DHA were higher in gray than white matter brain regions. For the entire human brain, the net DHA incorporation rate $J_{i n}$, the product of $\mathrm{k}^{*}$ and the unesterified plasma DHA concentration, equaled $3.8 \pm 1.7 \mathrm{mg} /$ day (figure 1). This net rate, approximating the net rate of DHA consumption by brain, is less than the suggested human diet DHA supplementation 200 mg per day of DHA (Kris-Etherton et al., 2000).

In an as yet unpublished study (Kim et al., submitted), we subjected rats post-weaning for 15 weeks to DHA-free diets having graded reductions in $\alpha$ LNA content below a dietary "sufficient" level containing 4.6\% $\alpha$-LNA (DeMar et al., 2004). While plasma DHA fell in rough proportion to the reduction in dietary $\alpha$-LNA, the brain DHA concentration surprisingly was maintained down to $1.7 \%$ dietary $\alpha$ LNA, suggesting that brain DHA does not track plasma DHA until quite large reductions in plasma concentration arise. In this regard, plasma DHA is reduced by $50 \%$ in vegetarians compared with omnivores (Rosell et al., 2005), despite there being no difference in overall mortality or mortality from any general cause between the two groups (Key et al., 2009). Together, the rodent and human data suggests that using the blood DHA concentration as a biomarker of brain DHA integrity may be incorrect. Thus, it would be of importance to determine whether brain consumption of DHA, measured with our intravenous infusion method in rodents or humans, compared with the brain concentration of DHA, measured by direct determination in rodents, is the major determinant of brain functional integrity by measuring consumption in relation to plasma DHA content in rats or in humans with the intravenous infusion method.

One approach that as has not been exploited sufficiently is the use of radiolabeled DHA to image its role in regional brain signal transduction and neuroplasticity using quantitative autoradiography in vivo. For example, 3 months after removing one eye in a rat, DHA incorporation from plasma into the contralateral brain regions, e.g. superficial gray matter of the superior colliculus and dorsal lateral geniculate nucleus, that normally were innervated by the eye 
that was removed, was significantly reduced, emphasizing a role for DHA in signaling and neuroplasticity that deserves to be exploited (Wakabayashi et al., 1995). DHA incorporation also was altered in an L1210 leukemia cells implanted in rat brain, suggesting a role for DHA in tumor metabolism (Nariai et al., 1994).

Several groups of $\mathrm{PLA}_{2}$ enzymes have been identified in the mammalian brain, and their specificity has been characterized based in vitro studies (Six and Dennis, 2000). Questions remain about their locations and functions in the intact organism, however. These include (1) AA-selective calcium-dependent cytosolic $\mathrm{CPLA}_{2}$ type IVA, which can be activated via multiple G-protein-coupled neuroreceptors, including serotonergic 5- $\mathrm{HT}_{2 \mathrm{~A} / 2 \mathrm{C}}$ receptors (Berg et al., 1998; Qu et al., 2005), and muscarinic $M_{1,3,5}$ receptors (Bayon et al., 1997), and the ionotropic N-methyl-D-aspartate(NMDA) receptor which when activated allows extracellular calcium into the cell (Basselin et al., 2006); (2) secretory presynaptic $\mathrm{SPLA}_{2}$ which requires a high calcium concentration $(20 \mathrm{mM})$ for activation, and (3) calcium-independent iPLA ${ }_{2}$, which is considered DHA-selective, and can be activated through both muscarinic and serotonergic receptors (DeGeorge et al., 1991; Garcia and Kim, 1997). Both $\mathrm{CPLA}_{2}$ and $\mathrm{PLA}_{2}$ have postsynaptic locations in mammalian brain (Ong et al., 1999; Ong et al., 2005).

Recognizing the in vitro enzyme selectivity of $\mathrm{CPLA}_{2}$ and $\mathrm{PLA}_{2}$ for $\mathrm{AA}$ and $\mathrm{DHA}$, respectively, we confirmed their in vivo dependencies on extracellularderived calcium in unanesthetized rats by showing that NMDA administration increased incorporation of intravenously injected radiolabeled $\mathrm{AA}$ but not of radiolabeled DHA into the brain (Ramadan et al., 2010) (figure 2). The results suggest that greater $\mathrm{AA}$ than $\mathrm{DHA}$ release during glutamate-induced excitotoxicity could cause brain cell damage since high concentrations of $\mathrm{AA}$ and its metabolites are considered to be neurotoxic and proinflammatory (Bazan et al., 1981).

We also confirmed a role for PPLA $_{2}-\mathrm{VIA}$ $\left(\mathrm{iPLA}_{2} \beta\right)$ in brain DHA signaling in vivo (Basselin et al., 2010; DeGeorge et al., 1991), consistent with evidence that this enzyme can be activated by calcium derived from intracellular calcium stores of the endoplasmic reticulum, thereby
DAILY DHA CONSUMPTION RATE BY HUMAN BRAIN

Horizontal PET images of incorporation coefficients ${ }^{1} k^{*}$ for DHA in healthy human volunteers following i.v. $\left[{ }^{11} \mathrm{C}\right] \mathrm{DHA}$

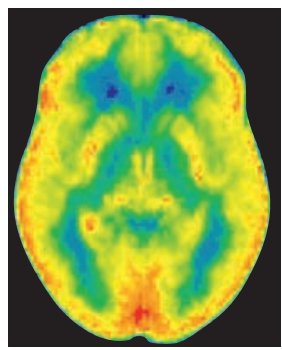

$\left[1-{ }^{11} \mathrm{C}\right] \mathrm{DHA}$
Global DHA Daily Consumption Rate $J_{\text {in }}=k^{*} C_{\text {plasma, } D H A}$ $3.8 \pm 1.7(\mathrm{SD}) \mathrm{mg} / \mathrm{brain} /$ day

1 Partial volume corrected

$C_{\text {plasma }, D H A}(\mathrm{nmol} / \mathrm{mL}): 2.63 \pm 1.17$

Figure 1. Daily DHA consumption rate by human brain. Measurements were performed by injecting $\left[1-{ }^{11} \mathrm{C}\right] \mathrm{DHA}$ intravenously in volunteers and using positron emission tomography (Umhau et al., 2009).

displacing it from calmodulin (Rosa and Rapoport, 2009). Mutations in the PLA2G6 gene encoding the enzyme occur in patients with idiopathic neuro-

degeneration plus brain iron accumulation and dystonia-parkinsonism without iron accumulation (Kurian et al., 2008), whereas mice lacking PLA2G6 show

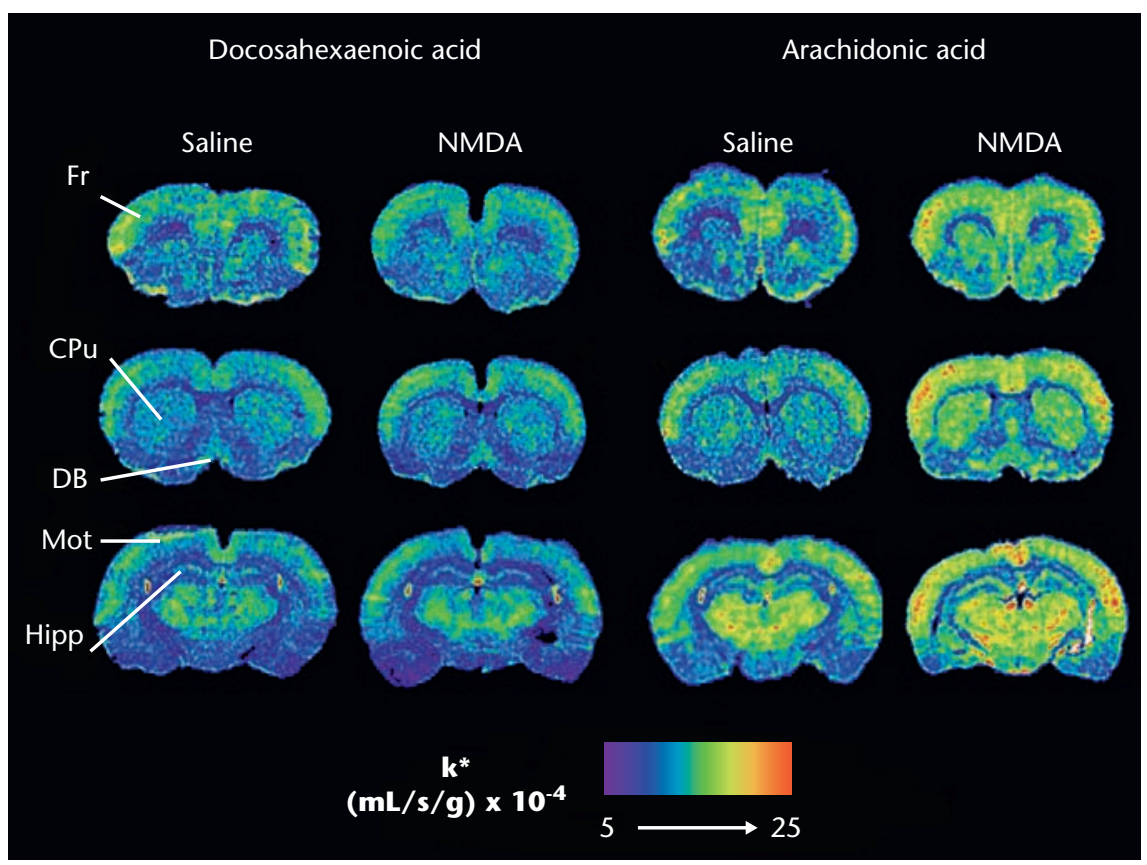

Figure 2. NMDA (25 mg/kg i.p.) initiates arachidonic but not docosahexaenoic acid signal in rat brain. Coronal autoradiographs of brains from rat injected with NMDA compared to animals injected with saline. FR, frontal cortex; $C P U$, caudate-putamen, DB, diagonal band; Mot, motor cortex; Hipp, hippocampus. Incorporation coefficients $k^{*}$ are color-coded. From (Ramadan et al., 2010). 
neurological dysfunction and significant neuropathology after 13 but not 4 months of age. We hypothesized that brain DHA metabolism and signaling in response to the cholinergic muscarinic $M_{1,3,5}$ agonist, arecoline (DeGeorge et al., 1991) would be reduced in 4month-old iPLA $A_{2} \beta$-deficient mice without overt neuropathology. Saline or arecoline (30 mg/kg) was administered to unanesthetized (homozygous, heterozygous or wildtype mice $\operatorname{PLA}_{2} \beta(-/-),(+/-)$, or $(+/+)$ mice), and $\left[1-{ }^{14} \mathrm{C}\right] \mathrm{DHA}$ was infused intravenously. DHA incorporation coefficients and rates representing DHA metabolism were determined using quantitative autoradiography in 81 brain regions. iPLA $2 \beta(-/-)$ and (+/-) mice compared with iPLA $\beta(+/+)$ mice showed widespread and significant baseline reductions in $k^{*}$ and $J_{\text {in }}$ for DHA. Arecoline increased both parameters in brain regions of $\mathrm{PLA}_{2} \beta(+/+)$ mice but quantitatively less so in $\mathrm{iPLA}_{2} \beta(-/-)$ and $\mathrm{PLA}_{2} \beta$ (+/-) mice (Basselin et al., 2010). Consistent with $\mathrm{PPLA}_{2} \beta^{\prime}$ s reported ability to selectively hydrolyze DHA from phospholipid in vitro, a genetic iPLA $2 \beta$ deficiency reduced brain DHA metabolism and signaling in vivo at baseline and following $M_{1,3,5}$ receptor activation by arecoline. Positron emission tomography might be used to image disturbed brain DHA metabolism in patients with PLA2G6 mutations.

\section{Conclusion}

Brain imaging of DHA incorporation (consumption) as a biomarker of DHA metabolism following a single intravenous injection of radiolabeled DHA may prove useful in studying the role of DHA in health and disease, and in investigating the influence of diet, in animal and humans. As noted above, in a study in which plasma DHA was reduced in relation to reduced dietary $\alpha$-LNA in rats subjected to 15 weeks of a DHA-free diet containing different $\alpha$ LNA content starting with $4.6 \%$ DHA (adequate diet), brain DHA did not follow plasma DHA but fell only after dietary DHA had declined by more than half, to $1.7 \% \quad \alpha$-LNA (Kim et al., submitted). Thus brain DHA did not track plasma DHA when the latter was reduced markedly by diet. A similar lack of tracking may occur in humans a well.

Another important issue is that brain DHA content and metabolism depend not only on diet, but also on the ability of the liver to synthesize DHA from circulating $\alpha$-LNA, making it critical to be able to assess liver synthesis under different dietary conditions. To address this issue, we have developed a method involving a constant intravenous infusion of heavy isotopically labeled precursor $\left[\mathrm{U}-{ }^{13} \mathrm{C}\right] \alpha$-LNA for $2 \mathrm{~h}$ in rats on a DHA containing diet, while measuring labeled and unlabeled n-3 PUFA in arterial plasma using negative chemical ionization GC-MS (Gao et al., 2009b). Newly synthesized esterified $\left[{ }^{13} \mathrm{C}\right] \mathrm{DHA}$, $\left[{ }^{13} \mathrm{C}\right] \mathrm{EPA}$, and $\left[{ }^{13} \mathrm{C}\right] \mathrm{DPA}(22: 5 \mathrm{n}-3)$ appeared in arterial plasma after $60 \mathrm{~min}$ of infusion, then their concentrations rose in an S-shaped manner. Esterified concentration $\times$ plasma volume data were fit with a sigmoidal equation, whose peak first derivatives provided synthesis rates of unlabeled EPA, DPA, and DHA. The DHA synthesis rate exceeded the published daily rat brain DHA consumption rate by 30 -fold, suggesting that liver synthesis from $\alpha$-LNA could maintain brain DHA homeostasis were DHA absent from the diet. Conversion rate from infused isotopically labeled EPA also were measured (Gao et al., 2009b). More recently, we showed that the synthesis rates from $\alpha$-LNA were markedly elevated when DHA was absent from the diet, as was expression of appropriate liver elongases and desaturases (Gao et al., unpublished). This stable isotope infusion method could be used to quantify whole-body DHA synthesis rates in humans in relation to consumption by brain and other organs, and fill out the equation that whole body DHA is the sum of dietary and hepatic inputs.

The ability to image labeled DHA incorporation into brain with quantitative autoradiography in rodents or with PET in humans provides an opportunity as a biomarker that remains to be exploited under different experimental and clinical conditions.

Acknowledgements. This study was supported entirely by the Intramural Program of the National Institute on Aging. No author has a conflict of interest with regard to the research.

\section{REFERENCES}

Basselin M, Chang L, Bell JM, Rapoport SI. Chronic lithium chloride administration attenuates brain NMDA receptor-initiated signaling via arachidonic acid in unanesthetized rats. Neuropsychopharmacology 2006; 31: 1659-74.

Basselin M, Rosa AO, Ramadan E, et al. Imaging decreased brain docosahexaenoic acid metabolism and signaling in iPLA2 $\beta$ (VIA)-deficient mice. J Lipid Res 2010; 51: 3166-73.

Bayon Y, Hernandez M, Alonso A, et al. Cytosolic phospholipase A2 is coupled to muscarinic receptors in the human astrocytoma cell line 1321N1: characterization of the transducing mechanism. Biochem / 1997; 323 (Pt 1): 281-7.

Bazan NG. Neuroprotectin D1-mediated anti-inflammatory and survival signaling in stroke, retinal degenerations, and Alzheimer's disease. J Lipid Res 2009; 50 (Suppl.): S400-5.

Bazan NG, Aveldano de Caldironi MI, Rodriguez de Turco EB. Rapid release of free arachidonic acid in the central nervous system due to stimulation. Prog Lipid Res 1981; 20: 523-9.

Berg KA, Maayani S, Goldfarb J, Scaramellini C, Leff P, Clarke WP. Effector pathwaydependent relative efficacy at serotonin type $2 \mathrm{~A}$ and $2 \mathrm{C}$ receptors: evidence for agonistdirected trafficking of receptor stimulus. $\mathrm{Mol}$ Pharmacol 1998; 54: 94-104.

Channing MA, Simpson N. Radiosynthesis of 1-[11C]polyhomoallylic fatty acids. J Labeled Compounds Radiopharmacol 1993; 33: 541-6.

Chen CT, Liu Z, Bazinet RP. Rapid deesterification and loss of eicosapentaenoic acid from rat brain phospholipids: an intracerebroventricular study. I Neurochem 2011; 116: 363-73.

Chen CT, Ma DW, Kim JH, Mount HT, Bazinet RP. The low density lipoprotein receptor is not necessary for maintaining mouse brain polyunsaturated fatty acid concentrations. J Lipid Res 2008; 49: 147-52.

Conquer JA, Tierney MC, Zecevic J, Bettger WJ, Fisher RH. Fatty acid analysis of blood plasma of patients with Alzheimer's disease, other types of dementia, and cognitive impairment. Lipids 2000; 35: 1305-12.

Contreras MA, Greiner RS, Chang MC, Myers CS, Salem N, Jr., Rapoport SI. Nutritional deprivation of alpha-linolenic acid decreases but does not abolish turnover and availability of unacylated docosahexaenoic acid and docosahexaenoyl-CoA in rat brain. I Neurochem 2000; 75: 2392-400.

DeGeorge JJ, Nariai T, Yamazaki S, Williams WM, Rapoport SI. Arecoline-stimulated brain incorporation of intravenously administered fatty acids in unanesthetized rats. I Neurochem 1991; 56: 352-5. 
DeGeorge JJ, Noronha JG, Bell JM, Robinson P, Rapoport SI. Intravenous injection of [114C]arachidonate to examine regional brain lipid metabolism in unanesthetized rats. J Neurosci Res 1989; 24: 413-23.

DeMar JC, Jr., Ma K, Bell JM, Igarashi M, Greenstein D, Rapoport SI. One generation of n-3 polyunsaturated fatty acid deprivation increases depression and aggression test scores in rats. J Lipid Res 2006; 47: 172-80.

DeMar JC, Jr., Ma K, Bell JM, Rapoport SI. Half-lives of docosahexaenoic acid in rat brain phospholipids are prolonged by 15 weeks of nutritional deprivation of $\mathrm{n}-3$ polyunsaturated fatty acids. I Neurochem 2004; 91: 1125-37.

DeMar JC, Jr., Ma K, Chang L, Bell JM, Rapoport SI. (-Linolenic acid does not contribute appreciably to docosahexaenoic acid within brain phospholipids of adult rats fed a diet enriched in docosahexaenoic acid. J Neurochem 2005; 94: 1063-76.

Farooqui AA, Horrocks LA, Farooqui T. Modulation of inflammation in brain: a matter of fat. I Neurochem 2007; 101: 577-99.

Gao F, Kiesewetter D, Chang L, et al. Wholebody synthesis-secretion rates of long-chain $\mathrm{n}-3$ PUFAs from circulating unesterified $\alpha$ linolenic acid in unanesthetized rats. I Lipid Res 2009a ; 50: 749-58.

Gao F, Kiesewetter D, Chang L, Ma K, Rapoport SI, Igarashi M. Whole-body synthesis-secretion of docosahexaenoic acid from circulating eicosapentaenoic acid in anesthetized rats. J Lipid Res 2009b ; 50: 2463-70.

Garcia MC, Kim HY. Mobilization of arachidonate and docosahexaenoate by stimulation of the 5-HT2A receptor in rat $\mathrm{C} 6$ glioma cells. Brain Res 1997; 768: 43-8.

Gavino GR, Gavino VC. Rat liver outer mitochondrial carnitine palmitoyltransferase activity towards long-chain polyunsaturated fatty acids and their CoA esters. Lipids 1991; 26: $266-70$.

Holman RT. Control of polyunsaturated acids in tissue lipids. J Am Coll Nutr 1986; 5: 183-211.

Igarashi M, DeMar JC, Jr., Ma K, Chang L, Bell JM, Rapoport SI. Docosahexaenoic acid synthesis from $\alpha$-linolenic acid by rat brain is unaffected by dietary n-3 PUFA deprivation. J Lipid Res 2007; 48: 1150-8.

Key TJ, Appleby PN, Spencer EA, Travis RC, Roddam AW, Allen NE. Mortality in British vegetarians: results from the European Prospective Investigation into Cancer and Nutrition (EPIC-Oxford). Am J Clin Nutr 2009; 89: 1613S-1619S.

Kim H-W, Rao JS, Rapoport SI, Igarashi M (submitted). Regulation of rat brain polyunsaturated fatty acid (PUFA) metabolism during graded dietary n-3 PUFA deprivation. Submitted.

Kris-Etherton PM, Taylor DS, Yu-Poth S, et al. Polyunsaturated fatty acids in the food chain in the United States. Am J Clin Nutr 2000; 71: 179S-88S.

Kurian MA, Morgan NV, MacPherson L, et al. Phenotypic spectrum of neurodegeneration associated with mutations in the PLA2G6 gene (PLAN). Neurology 2008; 70: 1623-9.

Nariai T, DeGeorge JJ, Greig NH, Genka S, Rapoport SI, Purdon AD. Differences in rates of incorporation of intravenously injected radiolabeled fatty acids into phospholipids of intracerebrally implanted tumor and brain in awake rats. Clin Exp Metastasis 1994; 12: 213-25.

Ong WY, Sandhya TL, Horrocks LA, Farooqui AA. Distribution of cytoplasmic phospholipase $\mathrm{A} 2$ in the normal rat brain. J Hirnforsch 1999; 39: 391-400.

Ong WY, Yeo JF, Ling SF, Farooqui AA. Distribution of calcium-independent phospholipase A2 (iPLA2) in monkey brain. J Neurocytol 2005; 34: 447-58.

Purdon D, Arai T, Rapoport S. No evidence for direct incorporation of esterified palmitic acid from plasma into brain lipids of awake adult rat. J Lipid Res 1997; 38: 526-30.

Qu Y, Villacreses N, Murphy DL, Rapoport SI. 5-HT2A/2C receptor signaling via phospholipase $\mathrm{A} 2$ and arachidonic acid is attenuated in mice lacking the serotonin reuptake transporter. Psychopharmacology (Berl) 2005; 180: 12-20.

Quinn JF, Raman R, Thomas RG, et al. Docosahexaenoic acid supplementation and cognitive decline in Alzheimer disease: a randomized trial. JAMA 2010; 304: 1903-11.

Ramadan E, Rosa AO, Chang L, Chen M, Rapoport SI, Basselin M. Extracellular-derived calcium does not initiate in vivo neurotransmission involving docosahexaenoic acid. J Lipid Res 2010; 51: 2334-40.

Rao JS, Ertley RN, DeMar JC, Jr., Rapoport SI, Bazinet RP, Lee HJ. Dietary n-3 PUFA deprivation alters expression of enzymes of the arachidonic and docosahexaenoic acid cascades in rat frontal cortex. Mol Psychiatry 2007; 12: 151-7.

Robinson PJ, Noronha J, DeGeorge JJ, Freed LM, Nariai T, Rapoport SI. A quantitative method for measuring regional in vivo fattyacid incorporation into and turnover within brain phospholipids: Review and critical analysis. Brain Res Brain Res Rev 1992; 17: 187-214.

Rosa AO, Rapoport SI. Intracellular- and extracellular-derived $\mathrm{Ca} 2+$ influence phospholipase A2-mediated fatty acid release from brain phospholipids. Biochim Biophys Acta 2009; 1791: 697-705.

Rosell MS, Lloyd-Wright Z, Appleby PN, Sanders TA, Allen NE, Key TJ. Long-chain $\mathrm{n}-3$ polyunsaturated fatty acids in plasma in British meat-eating, vegetarian, and vegan men. Am J Clin Nutr 2005; 82: 327-34.

Salem N, Jr., Litman B, Kim HY, Gawrisch K. Mechanisms of action of docosahexaenoic acid in the nervous system. Lipids 2001; 36: 945-59.

Six DA, Dennis EA. The expanding superfamily of phospholipase A2 enzymes: classification and characterization. Biochim Biophys Acta 2000; 1488: 1-19.

Strokin M, Sergeeva M, Reiser G. Role of Ca2 +-independent phospholipase $\mathrm{A} 2$ and $\mathrm{n}-3$ polyunsaturated fatty acid docosahexaenoic acid in prostanoid production in brain: perspectives for protection in neuroinflammation. Int / Dev Neurosci 2004; 22: 551-7.

Umhau JC, Zhou W, Carson RE, Rapoport SI, et al. Imaging incorporation of circulating docosahexaenoic acid into the human brain using positron emission tomography. J Lipid Res 2009; 50: 1259-68.

Wakabayashi S, Freed LM, Chang M, Rapoport SI. In vivo imaging of brain incorporation of fatty acids and of 2-deoxy-D-glucose demonstrates functional and structural neuroplastic effects of chronic unilateral visual deprivation in rats. Brain Res 1995; 679: $110-22$ 